Çukurova Üniversitesi Mühendislik Mimarlık Fakültesi Dergisi, 35(4), ss. 873-882, Aralık 2020

\title{
Haraptepe (Horzum-Adana) Pb-Zn Cevherleşmesinin Kökenine Genel Bir Yaklaşım
}

\author{
Yusuf URAS ${ }^{* 1}$, Cihan YALÇIN ${ }^{2}$, Mesut ÖZEN ${ }^{1}$ \\ ${ }^{1}$ KahramanmaraşS Sütçü Imam Üniversitesi, Mühendislik Mimarlkk Fakültesi, Jeoloji Mühendisliği \\ Bölümü, Kahramanmaraş \\ ${ }^{2}$ Sanayi ve Teknoloji Bakanllğı, Sanayi Bölgeleri Genel Müdürlügü̈, Ankara
}

Geliş tarihi: $13.11 .2020 \quad$ Kabul tarihi: 30.12 .2020

$\ddot{\mathbf{O z}}$

$\mathrm{Bu}$ çalışmanın amacı Adana ilinin kuzeydoğusunda yer alan Haraptepe (Horzum) cevherleşmesinin jeokimyasal özelliklerini ortaya koymaktır. Doğu Toroslarda yer alan cevher zonu Horzum $\mathrm{Pb}-\mathrm{Zn}$ yatağının bir koludur. Geyikdağı birliğine ait kayaçların gözlendiği bu alanda temelde Kaotik seri, üzerinde ise tektonik dokanak ile Çaltepe ve Seydişehir formasyonları gözlenir. Cevherleşme Orta Kambriyen yaşlı Çaltepe formasyonuna ait açık renkli kireçtaşları içerisinde bulunur. Cevherleşme $\mathrm{K} 10^{\circ} \mathrm{D}$ doğrultulu ve GD'ye eğimlidir. Epijenetik oluşumlu metalce zengin cevher, cep ve mercekler şeklinde olup stratabound karakterdedir. Cevherleşmede birincil sülfürlü mineraller; galenit, sfalerit, pirit ve çok az miktarda kalkopirit şeklindedir. İnceleme alanından derlenen cevherli örneklerin değerli metal, ana ve iz element analizleri sonucunda $\mathrm{Zn} \% 50$ 'ye kadar $\mathrm{Pb}$ ise $\% 25$ 'e kadar ulaşmaktadır. Yüzeyden alınan örneklerde $\mathrm{Zn}$ değeri ortalama $\% 30,5$ ve $\mathrm{Pb}$ ise \%11,4'tür. $\mathrm{Cu}$ değeri 1-14 ppm ve Mn 210-642 ppm arasında değişmekte olup Cd miktarı ile Ag miktarı ise ortalama $<0,5$ ppm'dir. Yapılan yeraltı sondajlarından derlenen örneklerin analiz sonuçları da yüzey örneklerine benzerlik sunar. Cevher mineralojisi ve jeokimyası değerlendirildiğinde Haraptepe cevherleşmesi Horzum Bölgesindeki diğer yataklara benzer bir karakter sergilemekte olup düşük $\mathrm{Cu}$ oranı ile de karbonat ornatım yataklarına benzer bir davranış sergiler.

Anahtar Kelimeler: Çaltepe formasyonu, Epijenetik, $\mathrm{Pb}-\mathrm{Zn}$ cevherleşmesi, Jeokimya, Haraptepe

\section{A General Approach to the Origin of Haraptepe (Horzum-Adana) Pb-Zn Mineralization}

\begin{abstract}
The aim of this study is to prove the geochemical characteristics of the Haraptepe (Horzum) mineralization where located in the northeast of Adana. The ore zone where in the eastern Taurus is a branch of the Horzum $\mathrm{Pb}-\mathrm{Zn}$ deposit. In this area, where rocks belonging to the Geyikdağ 1 unit are observed, the Chaotic series at the base and the Çaltepe and Seydişehir formations with tectonic contact are observed on it. Mineralization is found within the light colored limestones belonging to the Middle
\end{abstract}

*Sorumlu yazar (Corresponding author): Yusuf URAS, uras74@gmail.com 
Cambrian aged Çaltepe formation. The mineralization strikes $\mathrm{N} 10^{\circ} \mathrm{E}$ and dips to SE. The epigenetically formed metal-rich ore is in the form of pockets and lenses and has a stratabound character. Primary sulphide minerals in mineralization; It is in the form of galena, sphalerite, pyrite and very little chalcopyrite respectively. As a result of the precious metal, main and trace element analyzes of the ore samples collected from the study area, $\mathrm{Zn}$ reaches $50 \%$ and $\mathrm{Pb}$ reaches $25 \%$. In samples taken from the surface, the average $\mathrm{Zn}$ value is $30.5 \%$ and $\mathrm{Pb}$ is $11.4 \%$. Cu value varies between $1-14 \mathrm{ppm}$ and Mn 210-642 ppm, Cd content and Ag amount are $<0.5 \mathrm{ppm}$ on average. The analysis results of the samples collected from the underground drillings are also similar to the surface samples. Considering the ore mineralogy and geochemistry, the Haraptepe mineralization exhibits a similar character to other deposits in the Horzum Region, and with its low $\mathrm{Cu}$ ratio, it exhibits a similar behavior to carbonate replacement deposits.

Keywords: Çaltepe formation, Epigenetic, $\mathrm{Pb}-\mathrm{Zn}$ Mineralization, Geochemsitry, Haraptepe

\section{GİRIȘ}

Anatolid-Torid Bloğu içerisinde gösterilen Toros Orojenik Kuşağı $[1,2]$ Avrupa'dan Asya'ya doğru uzanan Tetis Metalojenik Kuşağı üzerinde yer alır $[3,4]$. Bu kuşak önemli maden yataklarına ev sahipliği yapmakta olup bu kuşak içerisinde yer alan Toroslarda da karbonatlı kayaçlar içerisinde önemli $\mathrm{Pb}-\mathrm{Zn}$ yataklarının olduğu bilinmektedir $[5,6]$. Batı, Orta ve Doğu Toroslar olarak 3'e ayrilan bu kuşak (SSekil 1a), tektonik dilimlerin bir arada olduğu birliklerden oluşmaktadır [7]. Bu birlikler içerisindeki karbonatlı kayaçlar ile ilişsili birçok $\mathrm{Pb}-\mathrm{Zn}$ cevherleşmeleri bulunmaktadır [8-27].

Özbek [28], Orta ve Doğu Toroslardaki karbonatlı kayaçlar ile ilişkili $\mathrm{Pb}-\mathrm{Zn}$ yataklarında Karbon ve Oksijen izotop analizleri yapmış ve yan kayaç olan kireçtaşlarının denizel şelf karbonatlarına ait olduğunu belirtmiştir. Hanilçi ve arkadaşları [6] Toros kuşağı boyunca karbonatlı kayaçlarla ilişkili olan $\mathrm{Pb}-\mathrm{Zn}$ cevherleşmelerinin MVT ve SEDEX tipinde olduğunu, Horzum cevherleşmesinin de karbonat ornatım yatağı olduğunu belirtmiştir.

Megaw [29] ve Akyüz [30], Horzum bölgesindeki cevherleşmenin jeokimya, cevher mineralojisi, mineral kimyası, sıvı kapanımı ve izotop jeokimyası çalışmalarını yapmış ve cevherleşmenin karbonat ornatım yatağı olduğunu belirtmiştir.

Adana kuzeyinde yer alan Horzum Pb-Zn cevherleşmesinde [13], cevher üretimi 500.000 ton
$\mathrm{ZnCO}_{3}$ ve 400.000 ton da $\mathrm{ZnS}$ şeklindedir [31]. Doğu Toros Orojenik kuşağının batısında yer alan bu bölgede (Şekil 1b) farklı lokasyonlarda cevherleşmeler bulunmaktadır. Bu cevherleşmeler güneyden kuzeye doğru; Suluhan, Horzum ocaklar ve Harap kayası şeklindedir [30].

Cevherleşmelerin (Horzum) kalınlığ 1 ortalama 20-25 m, genişliği 40-50 uzunluğu ise $80-100 \mathrm{~m}$ şeklindedir [32]. Epijenetik oluşumlu cevherleşmeler Orta-Üst Kambriyen yaşlı karbonatlı kayaçlardaki eklemlerde gözlenmekte ve stratabound karakterdedir [6,31,32]. Cevher parajenezinde sfalerit, galenit, pirit, kalokopirit, arsenopirit, bornit, arjantit, markazit, kalkozit, simitsonit, hidrozinkit, götit, limonit, serüzit, barit, kuvars ve kalsit bulunmaktadır $[6,31,32]$.

Sıvı kapanımı çalışmalarında elde edilen ortalama $235^{\circ} \mathrm{C}$ oluşum sicaklık değeri, cevher parajenezindeki bornit, arsenopirit, arjantit ve karbonat minerallerinin varlığı [6] Horzum bölgesindeki cevherleşmelerin karbonat ornatımı tipinde olduğunu göstermektedir.

Horzum bölgesindeki farklı lokasyonlarda olan cevher zonlarından olan Haraptepe cevher zonunun jeolojisi, mineralojisi ve jeokimyasının ayrıntılı olarak belirlenmesi bölgedeki diğer oluşumlar için de önem arz etmektedir. Bu çalışma ile Horzum cevherleşmesi içerisinde yer alan Haraptepe cevherleşmesinin 1/1000 ölçekli maden jeoloji haritası, mineralojisi ve jeokimyası ortaya konularak, cevherleşmenin kökensel özelliklerine genel bir yaklaşım ortaya konulmuştur. 

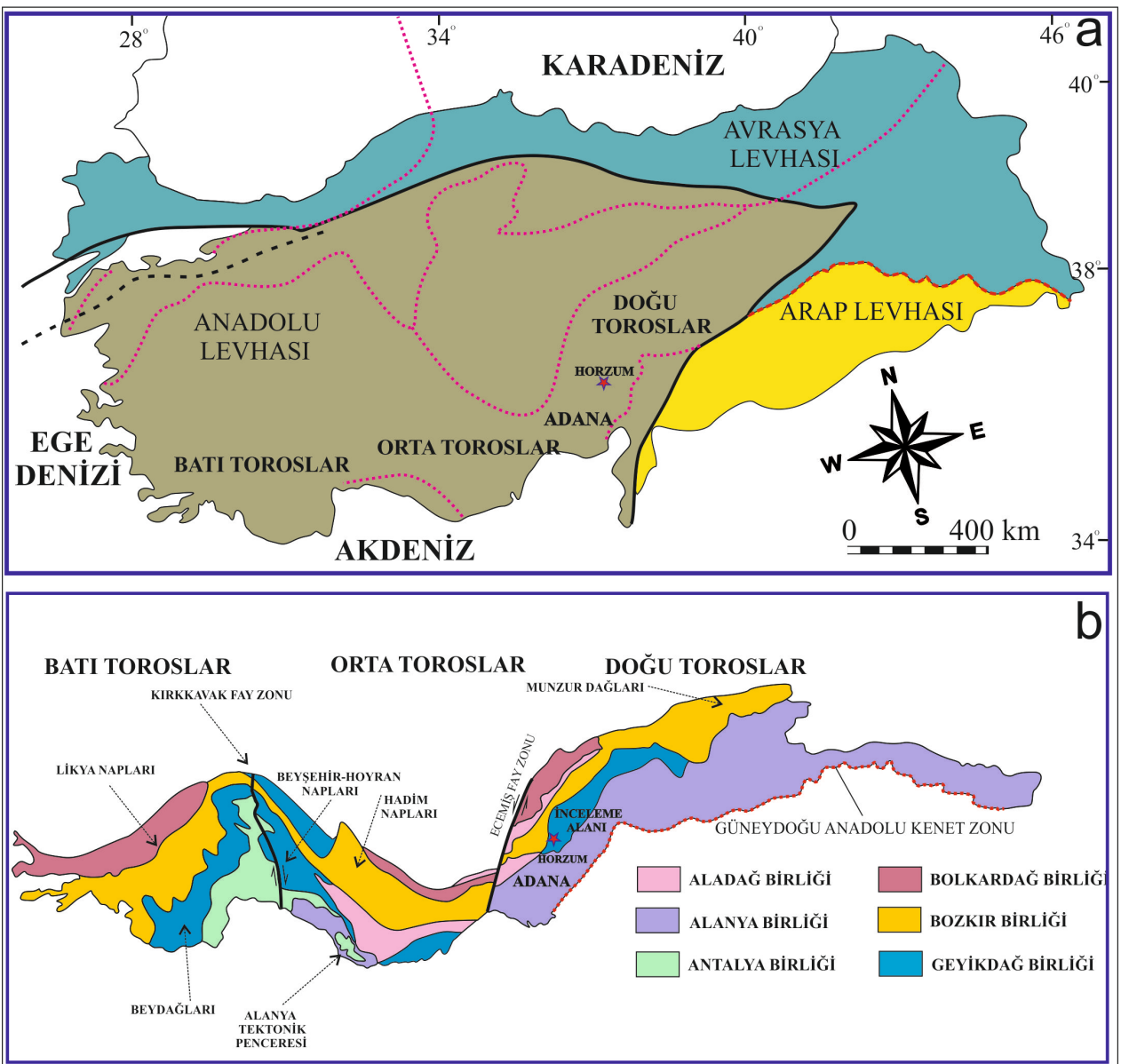

Şekil 1. a. İnceleme alanının tektonik ve b. Toros Orojenik kuşağındaki konumu (Işsk, [33]'den değiştirilmiştir)

\section{GENEL JEOLOJI}

Neotetis okyanusunun kollarının kapanması ile [34] Toros Orojenik Kuşağ 1 boyunca Prekambriyen-Mesozoyik yaşlı kayaçlar bir arada gözlenmektedir [7]. $\mathrm{Bu}$ birimlerin oluşturduğu tektono-stratigrafik istifler sebebiyle de tektonik birlikler tanımlanmıştır [7]. Bu birlikler Aladağ, Bozkır, Antalya, Bolkardağı, Alanya ve Geyikdağı ve Bolkardağı şeklindedir. İnceleme alanında Geyikdağı birliğine ait kayaçlar bulunmaktadır (Şekil 1b).

Geyikdağı Birliği, Kambriyen-Tersiyer yaş aralığındaki şelf tipi karbonat ve kırıntılı kayaçlardan oluşmaktadır [35-37]. İnceleme alanında ise temelde Usta ve arkadaşları [38] tarafindan adlandırılan Kaotik seri bulunmaktadır (Şekil 2). Bu birim kumtaşı, şeyl, silttaşı, dayk, sil ve farkl 1 boyutlardaki kuvarsit, dolomit ve kireçtaşı bloklarından oluşmaktadır [38]. Usta ve arkadaşları [38] tektonik kuvvetlerin etkili olduğu sığ denizel ortamda çökelen bu serinin yaşını Geç Kretase olarak belirlemiştir.

Kaotik seriden oluşan temel üzerine ise Geyikdağ 1 birliğine ait sedimanter kayaçlar tektonik olarak gelmektedir (Şekil 2). Tabandan tavana doğru ise Çaltepe formasyonuna ait [39] dolomitik kireçtaş1, koyu gri kireçtaşı ve kristalize kireçtaşı birimleri yer almakta, üst seviyelerde ise alacalı kireçtaşı, nodüler kireçtaşı ve şeyl birimlerinden oluşan 
Seydişehir formasyonu [37,40,41] yer almaktadır (Şekil 2). Birbirleri ile uyumlu olan bu birimler yer yer geçişlidir [41]. Çaltepe formasyonu Orta Kambriyen, Seydişehir formasyonu ise Geç Kambriyen-Ordovisiyen yaşlıdır [37,41].

Horzum bölgesindeki Mesozoyik yaşlı kayaçlarda KB uzanımlı bindirme fayları gözlenmektedir [42]. Bölgenin Ecemiş fayına yakın olması sebebiyle de makaslama zonları gözlenmektedir [42]. Yapılan 1/1000 ölçekli jeoloji haritasında da bölgede yaklaşık D-B uzanımlı doğrultu atımlı fayların geliştiği, bindirme düzleminin yaklaşık olarak KDGB uzanımlı olduğu, bu bindirme düzlemini ise yer yer kesen eğim atımlı fay gruplarının olduğu belirlenmiştir (Şekil 2). Fayların etkisiyle farklı birimlerin yan yana geldiği görülmektedir.

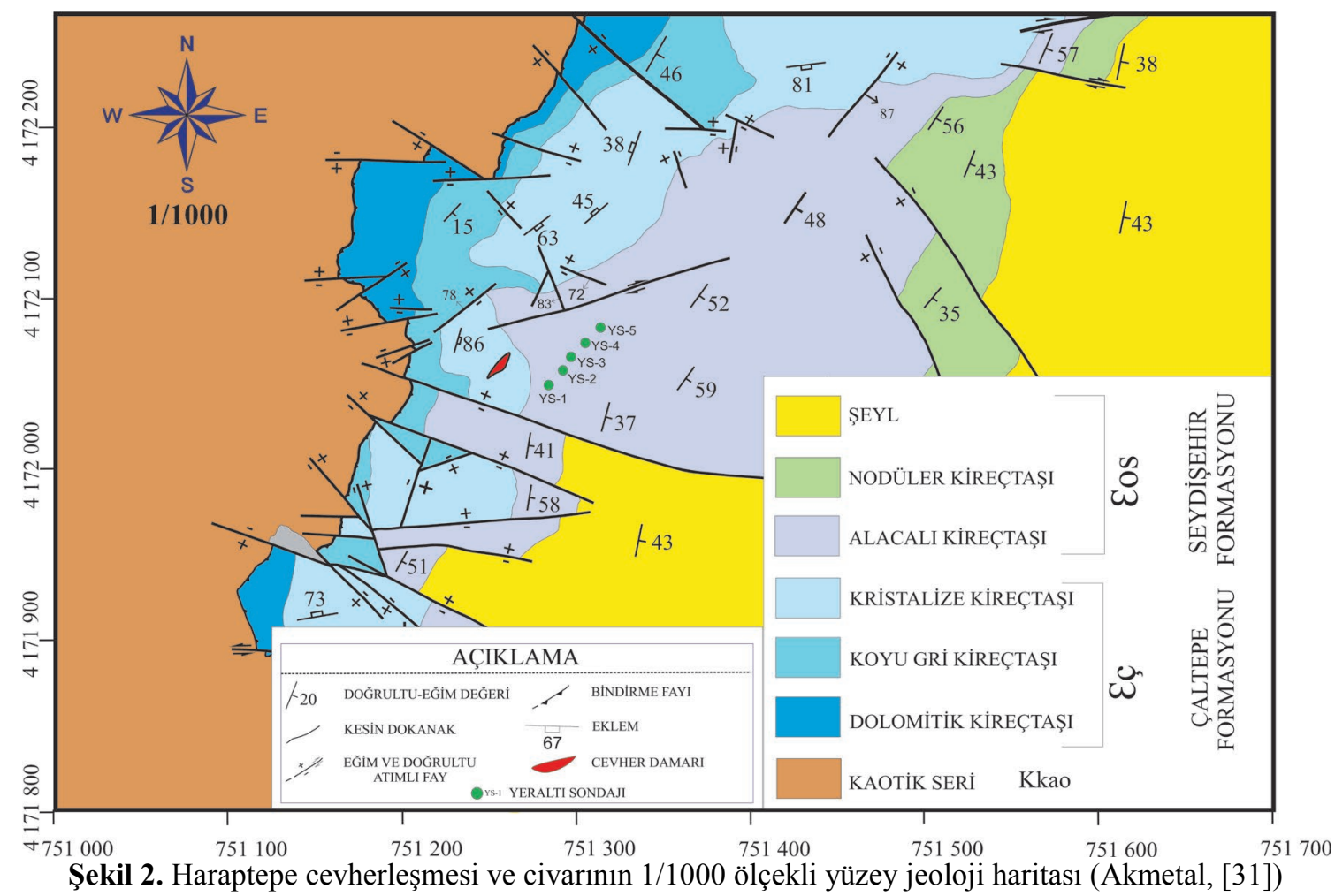

\section{MATERYAL VE METOD}

İnceleme alanı Adana ilinin sınırları içerisinde yer alan Kozan ilçesine bağlı Horzum Kasabası Haraptepe bölgesi Kurşun-Çinko yataklarını kapsamaktadır. $\mathrm{Bu}$ bölgede yeni bulunan Haraptepe cevher zonunun 1/1000 ölçekli yüzey jeoloji haritası hazırlanmıştır. Haritalama çalışmalarında Harita Genel Komutanlığı'ndan alınan UTM koordinatları kullanılmış ve tüm topografya ve jeoloji ölçüm/gözlem noktalarının konumu GPS ile hassas olarak belirlenmiştir.
Haritalama esnasında cevher ve yankayaçlardan örnekler derlenmiştir. $\mathrm{Bu}$ örneklerin mineral parajenezinin belirlenmesi amaciyla İstanbul Teknik Üniversitesi Jeokimya Araştırma Laboratuvarında (ITÜ̈-JAL) cevher mikroskobisi çalışmaları gerçekleştirilmiştir. Ayrıca daha önceden açılan galerilerde 5 adet yer altı sondaj1 gerçekleştirilmiştir. Sondajdan (5 farklı sondaj noktasından toplam 10 adet) ve yüzeyden derlenen (20 adet) cevher örneklerinin değerli metal, ana ve iz element analizleri İTÜ-JAL Labortauvarında ICP-MS cihazında yaptırılmıştır. 


\section{CEVHERLEŞME}

Horzum cevherleşmesi Paleozoyik yaşlı karbonatlı kayaçlar içerisinde K20D doğrultusu boyunca $9 \mathrm{~km}$ kesintili olarak bulunmaktadır [30]. Haraptepe cevherleşmesi sadece Orta Kambriyen yaşlı [38] Çaltepe formasyonuna ait kireçtaşı içinde K10D doğrultulu bir şekilde bulunmaktadır (Şekil 2). Cevher damarının eğimi ise güneydoğuya doğrudur.

Epijenetik oluşumlu metalce zengin cevher, cep ve mercekler şeklinde olup stratabound karakterdedir. Cevherli seviyelerin alt ve üst dokanağında yer alan diğer kireçtaşlarında ise $\mathrm{Pb}-\mathrm{Zn}$ mineralleşmesi görülmemektedir.

Cevherleşme, sülfürlü ve karbonatlı zonlardan oluşmaktadır. Sülfürlü cevher sfalerit, galenit, pirit ve çok seyrek kalkopirit, karbonatlı cevher ise simitsonit, zinkit, limonit gibi ikincil minerallerden
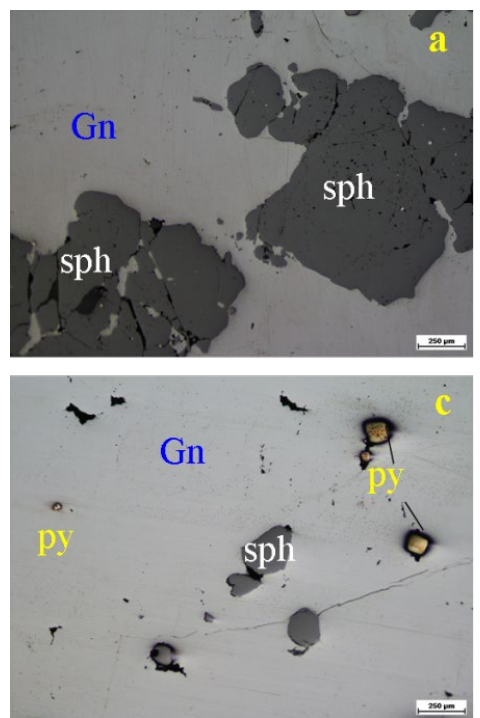

Şekil 3. Cevher minerallerinin mikroskobik görünümü, Gn: galenit, sph: sfalerit, ccp: kalkopirit, py: pirit

Pirit $\left(\mathrm{FeS}_{2}\right)$; az miktarda izlenmekte ve galenit içinde kapanımlar halinde gözlenmektedir (Şekil 3c). Pirit kristal boyutları birkaç mikronla 0,5-0,6 $\mathrm{mm}$ arasında değişmektedir. Bazı iri piritler, kendi aralarında kenetli kristal toplulukları oluşturmaktadır.
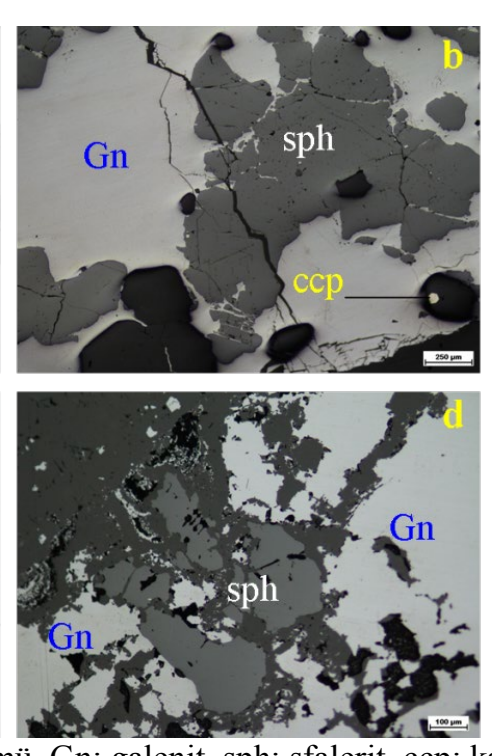

oluşur. Diğer gang mineralleri ise kalsit, barit ve kuvarsdır.

Cevher petrografisi çalışmalarında galenit, sfalerit, pirit ve kalkopirit tespit edilmiştir (Şekil 3). Bu sülfürlü minerallerin özellikleri aşağıda ayrıntılı bir şekilde verilmiştir.

Sfalerit (ZnS); çok fazla miktarda izlenmektedir. $\mathrm{Bu}$ nedenle cevher "masif sfalerit" cevheri olarak adlandırılabilir. Sfalerit çok iri taneli ve kataklastik yapılıdır (Şekil 3 a,b). Sfaleritin kataklastik çatlakları ve kristal araları ufak kristalli kalsit gang1 tarafından doldurulmuştur. Sfaleritin iç yansımaları sarımsı-kahverengi ile kahverengi arasında lamelli ikizlenmeler göstermektedir.

Galenit $(\mathrm{PbS})$; çok fazla miktarda gözlenmekte olup yarı özşekili kristaller halinde bulunmaktadır (Şekil 3 a,b,c,d). Masif galenitlerin çatlaklarında genellikle anglesit ve çok ender olarak da seruzitler oluşmuştur.

Kalkopirit $\left(\mathrm{CuFeS}_{2}\right)$; eser miktarda ve çok ufak ayrışım ve kapanım tanecikleri halinde bulunmaktadır (Şekil 3b). 


\section{JEOKIMYY}

İnceleme alanından derlenen cevherli örneklerin değerli metal, ana ve iz element analizleri gerçekleştirilmiş̧ir (Çizelge 1). Yapılan analizler sonucunda $\mathrm{Zn} \% 50$ 'ye kadar $\mathrm{Pb}$ ise \%25'e kadar ulaşmaktadır. Yüzeyden alınan (mostra) örneklerde $\mathrm{Zn}$ içeriği ortalama $\% 30,5$ ve $\mathrm{Pb}$ ise \%11,4'tür. $\mathrm{Cu}$ içeriği 1-14 ppm ve $\mathrm{Mn}$ 210-642 ppm arasında değişmekte olup Cd miktarı ile Ag miktarı ise $<0,5$ ppm'dir.

Cizelge 1. İnceleme alanından derlenen cevherli örneklerin jeokimyasal analiz sonuçları

\begin{tabular}{|c|c|c|c|c|c|c|c|c|c|c|c|c|c|c|c|c|c|}
\hline $\begin{array}{c}\text { Önek } \\
\text { no: }\end{array}$ & $\begin{array}{c}\mathbf{Z n} \\
\mathbf{\%}\end{array}$ & $\begin{array}{c}\mathbf{P b} \\
\mathbf{\%}\end{array}$ & $\begin{array}{c}\mathbf{C u} \\
\mathbf{p p m}\end{array}$ & $\begin{array}{c}\mathbf{F e} \\
\mathbf{\%}\end{array}$ & $\begin{array}{c}\mathbf{A g} \\
\mathbf{p p m}\end{array}$ & $\begin{array}{c}\mathbf{A l} \\
\mathbf{\%}\end{array}$ & $\begin{array}{c}\mathbf{B a} \\
\mathbf{p p m}\end{array}$ & $\begin{array}{c}\mathbf{B i} \\
\mathbf{p p m}\end{array}$ & $\begin{array}{c}\mathbf{C a} \\
\mathbf{\%}\end{array}$ & $\begin{array}{c}\mathbf{C d} \\
\mathbf{p p m}\end{array}$ & $\begin{array}{c}\mathbf{C o} \\
\mathbf{p p m}\end{array}$ & $\begin{array}{c}\mathbf{M g} \\
\mathbf{\%}\end{array}$ & $\begin{array}{c}\mathbf{M n} \\
\mathbf{p p m}\end{array}$ & $\begin{array}{c}\mathbf{M o} \\
\mathbf{p p m}\end{array}$ & $\begin{array}{c}\mathbf{N a} \\
\mathbf{\%}\end{array}$ & $\begin{array}{c}\mathbf{N i} \\
\mathbf{p p m}\end{array}$ & $\begin{array}{c}\mathbf{P} \\
\mathbf{\%}\end{array}$ \\
\hline 1 & 12 & 8 & 1 & 0,05 & $<0,5$ & 0,02 & 10 & $<2$ & 37,1 & $<0,5$ & 4 & 0,15 & 420 & $<1$ & 0,01 & 4 & $<10$ \\
\hline 2 & 9 & 3 & 1 & 0,06 & $<0,5$ & 0,03 & 10 & $<2$ & 37,4 & $<0,5$ & 5 & 0,12 & 463 & 1 & 0,02 & 5 & 40 \\
\hline 3 & 7 & 1 & $<1$ & 0,04 & $<0,5$ & 0,02 & 10 & $<2$ & 37,1 & $<0,5$ & 4 & 0,14 & 345 & 1 & 0,01 & 2 & $<10$ \\
\hline 4 & 5 & 1 & $<1$ & 0,02 & $<0,5$ & 0,01 & 10 & $<2$ & 37,5 & $<0,5$ & 3 & 0,12 & 226 & 1 & 0,01 & 3 & $<10$ \\
\hline 5 & 24 & 7 & 2 & 0,2 & $<0,5$ & 0,12 & 50 & $<2$ & 35,5 & $<0,5$ & 2 & 0,13 & 210 & $<1$ & 0,02 & 5 & $<10$ \\
\hline 6 & 20 & 5 & 3 & 0,32 & $<0,5$ & 0,32 & 30 & $<2$ & 35,9 & $<0,5$ & 4 & 0,72 & 450 & $<1$ & 0,02 & 4 & 480 \\
\hline 7 & 18 & 5 & 2 & 0,15 & $<0,5$ & 0,04 & 20 & $<2$ & 37,8 & $<0,5$ & 5 & 0,45 & 642 & $<1$ & 0,01 & 2 & 50 \\
\hline 8 & 24 & 8 & 1 & 0,14 & $<0,5$ & 0,02 & 15 & $<2$ & 37 & $<0,5$ & 3 & 0,6 & 502 & 1 & 0,01 & 3 & 15 \\
\hline 9 & 19 & 5 & 2 & 0,1 & $<0,5$ & 0,02 & 25 & $<2$ & 37 & $<0,5$ & 2 & 0,17 & 471 & 1 & 0,02 & 2 & $<10$ \\
\hline 10 & 23 & 6 & 3 & 0,09 & $<0,5$ & 0,03 & 35 & $<2$ & 37,6 & $<0,5$ & 4 & 0,16 & 495 & $<1$ & 0,02 & 4 & $<10$ \\
\hline 11 & 14 & 5 & 3 & 0,05 & $<0,5$ & 0,02 & 15 & $<2$ & 38,2 & $<0,5$ & 1 & 0,14 & 233 & $<1$ & 0,01 & 3 & 25 \\
\hline 12 & 10 & 3 & 1 & 0,45 & $<0,5$ & 0,99 & 120 & $<2$ & 34,2 & $<0,5$ & 2 & 0,31 & 410 & $<1$ & 0,05 & 5 & 250 \\
\hline 13 & 9 & 2 & 3 & 0,15 & $<0,5$ & 0,06 & 25 & $<2$ & 38,4 & $<0,5$ & 3 & 0,16 & 361 & $<1$ & 0,01 & 2 & 40 \\
\hline 14 & 6 & 3 & 2 & 0,05 & $<0,5$ & 0,04 & 15 & $<2$ & 37,5 & $<0,5$ & 4 & 0,16 & 228 & $<1$ & 0,01 & 3 & 20 \\
\hline 15 & 14 & 2 & 3 & 0,35 & $<0,5$ & 0,98 & 150 & $<2$ & 35 & 0,7 & 4 & 0,3 & 426 & $<1$ & 0,09 & 5 & 270 \\
\hline 16 & 13 & 3 & 1 & 0,04 & $<0,5$ & 0,03 & 15 & $<2$ & 36,2 & $<0,5$ & 3 & 0,15 & 323 & $<1$ & 0,01 & 4 & 20 \\
\hline 17 & 12 & 7 & 3 & 0,03 & $<0,5$ & 0,01 & 25 & $<2$ & 36,5 & $<0,5$ & 3 & 0,17 & 332 & $<1$ & 0,01 & 5 & 50 \\
\hline 18 & 9 & 10 & 2 & 0,08 & $<0,5$ & 0,05 & 30 & $<2$ & 36,8 & $<0,5$ & 4 & 0,16 & 336 & $<1$ & 0,02 & 5 & 20 \\
\hline 19 & 50 & 25 & 14 & 0,98 & $<0,5$ & 0,02 & 20 & $<2$ & 34,6 & $<0,5$ & 2 & 0,14 & 418 & $<1$ & 0,01 & 5 & 30 \\
\hline 20 & 7 & 5 & 4 & 0,09 & $<0,5$ & 0,05 & 80 & $<2$ & 38,2 & $<0,5$ & 3 & 0,14 & 430 & $<1$ & 0,02 & 6 & 30 \\
\hline
\end{tabular}

İnceleme alanında ayrıca yer altı galerilerde gerçekleştirilen sondajlardaki cevher örneklerinin analizi sonucunda $\mathrm{Zn} \% 26$ 'ya kadar $\mathrm{Pb}$ ise \%15'e kadar ulaşmaktadır (Çizelge 2). Sondaj örneklerine bakıldığında $\mathrm{Zn}$ değeri ortalama \%19 ve $\mathrm{Pb}$ ise \%5,9'dur. Cu değeri 1-4 ppm ve Mn 215-650 ppm arasında değişmekte olup $\mathrm{Cd}$ miktarı ile $\mathrm{Ag}$ miktarının ortalama değeri ise $<0,5$ ppm'dir.

Çizelge 2. İnceleme alanında yeraltı sondajlarından derlenen cevherli örneklerin jeokimyasal analiz sonuçları

\begin{tabular}{|c|c|c|c|c|c|c|c|c|c|c|c|c|c|c|c|c|c|}
\hline $\begin{array}{c}\text { Örnek } \\
\text { no: }\end{array}$ & $\begin{array}{c}\mathrm{Zn} \\
\% \\
\end{array}$ & $\begin{array}{c}\mathrm{Pb} \\
\% \\
\end{array}$ & $\begin{array}{c}\mathrm{Cu} \\
\mathrm{ppm}\end{array}$ & $\begin{array}{l}\text { Fe } \\
\%\end{array}$ & $\begin{array}{c}\text { Ag } \\
\text { ppm }\end{array}$ & $\begin{array}{l}\text { Al } \\
\%\end{array}$ & $\begin{array}{c}\text { Ba } \\
\text { ppm }\end{array}$ & $\begin{array}{c}\text { Bi } \\
\text { ppm }\end{array}$ & $\begin{array}{c}\text { Ca } \\
\% \\
\end{array}$ & $\begin{array}{c}\text { Cd } \\
\text { ppm }\end{array}$ & $\begin{array}{c}\text { Co } \\
\text { ppm }\end{array}$ & $\begin{array}{c}\text { Mg } \\
\% \\
\end{array}$ & $\begin{array}{c}\text { Mn } \\
\text { ppm }\end{array}$ & $\begin{array}{c}\text { Mo } \\
\text { ppm }\end{array}$ & $\begin{array}{c}\mathrm{Na} \\
\% \\
\end{array}$ & $\begin{array}{c}\mathrm{Ni} \\
\text { ppm }\end{array}$ & $\begin{array}{c}\mathbf{P} \\
\% \\
\end{array}$ \\
\hline YS1 & 20 & 8 & $<1$ & 3 & $<0,5$ & 0,03 & 10 & $<2$ & 37,1 & $<0,5$ & 4 & 0,14 & 450 & $<1$ & 0,01 & 4 & $<10$ \\
\hline YS2 & 15 & 3 & $<1$ & 4 & $<0,5$ & 0,02 & 10 & $<2$ & 37,4 & $<0,5$ & 5 & 0,15 & 420 & 1 & 0,01 & 4 & 40 \\
\hline YS3 & 9 & 3 & $<1$ & 6 & $<0,5$ & 0,01 & 10 & $<2$ & 37,1 & $<0,5$ & 4 & 0,13 & 420 & 1 & 0,01 & 4 & $<10$ \\
\hline YS4 & 9 & 4 & $<1$ & 4 & $<0,5$ & 0,02 & 10 & $<2$ & 37,5 & $<0,5$ & 3 & 0,13 & 412 & 1 & 0,01 & 3 & $<10$ \\
\hline YS5 & 26 & 4 & 3 & 5 & $<0,5$ & 0,15 & 50 & $<2$ & 35,5 & $<0,5$ & 2 & 0,11 & 215 & $<1$ & 0,02 & 3 & $<10$ \\
\hline YS6 & 24 & 2 & 2 & 6 & $<0,5$ & 0,21 & 30 & $<2$ & 35,9 & $<0,5$ & 4 & 0,82 & 460 & $<1$ & 0,02 & 5 & 480 \\
\hline YS7 & 17 & 8 & 3 & 5 & $<0,5$ & 0,06 & 20 & $<2$ & 37,8 & $<0,5$ & 5 & 0,5 & 650 & $<1$ & 0,02 & 4 & 50 \\
\hline YS8 & 26 & 15 & 2 & 4 & $<0,5$ & 0,04 & 15 & $<2$ & 37 & $<0,5$ & 3 & 0,8 & 550 & 1 & 0,01 & 3 & 15 \\
\hline YS9 & 24 & 7 & 4 & 5 & $<0,5$ & 0,05 & 25 & $<2$ & 37 & $<0,5$ & 2 & 0,2 & 475 & 1 & 0,01 & 5 & $<10$ \\
\hline YS10 & 20 & 5 & 4 & 2 & $<0,5$ & 0,04 & 35 & $<2$ & 37,6 & $<0,5$ & 4 & 0,19 & 485 & $<1$ & 0,01 & 4 & $<10$ \\
\hline
\end{tabular}


Tüm bu veriler ışı̆̆ında yüzeyden alınan örnekler ile sondaj örneklerinin benzer jeokimyasal davranış gösterdiği ve cevher zonunda sfalerit varlığının galenlere oranla daha fazla olduğu tespit edilmiştir.

\section{TARTIŞMA}

Türkiye'de karbonatlı kayaçlar ile ilişkili birçok $\mathrm{Pb}-\mathrm{Zn}$ yatağı olduğu bilinmektedir [6]. Orta ve Doğu Toroslarda ise Paleozoyik yaşlı karbonatlı kayaçlar ile Jura yaşlı kireçtaşlarında $\mathrm{Pb}-\mathrm{Zn}$ zenginleşmeleri bulunmaktadır [43]. Zhou ve arkadaşları [44-45] Çin'in güneydoğusunda Paleotetis'in kapanmasi sonucunda karbonatlı kayaçlarda epijenetik oluşumlu damar tipi $\mathrm{Pb}-\mathrm{Zn}$ cevherleşmelerinin bulunduğunu ve mineral parajenezinde de galenit, sfalerit, barit ve floritin olduğunu belirtmiştir. Uras ve arkadaşları [46] benzer oluşumun Kahramanmaraş kuzeydoğusundaki Helete bölgesinde de olduğunu belirtmiştir.

Karbonat ornatım yatakları ilk kez Megaw ve arkadaşları [47] tarafından tanımlanmış ve Türkiye'nin farklı lokasyonlarında da bu tip yatakların olduğu belirtilmiştir [6,48]. Horzum cevherleşmesinin jeokimya, cevher mineralojisi, mineral kimyası, siv1 kapanımı ve izotop jeokimyası özellikleri yatağın karbonat ornatım yatağı olduğunu göstermektedir [6,29-30]. Megaw ve arkadaşları [47] tarafindan tanımlanan karbonat ornatım yataklarında olduğu gibi Horzum cevherleşmesinde düşük bakır oranı bulunmaktadır.

Adana Horzum bölgesinde $\mathrm{Pb}-\mathrm{Zn}$ üretim çalışmaları 1970 yılında Adana madencilik A.Ş tarafindan başlatılmış ve güneyden kuzeye doğru farklı lokasyonlarda cevher zonları belirlenmiștir [30]. $\mathrm{Bu}$ lokasyonlardaki cevherleşmeler birbirlerine benzer karakter sergilemektedir. Haraptepe cevher zonu da jeolojik ve jeokimyasal özellikleri ile Horzum yatağının bir parçası olduğunu göstermektedir.

\section{SONUÇ}

$\mathrm{Bu}$ çalışma ile Haraptepe cevherleşmesinin cevheryan kayaç ilişkisi ortaya konulmuş ve ile 1/1000 ölçekli jeoloji haritası ilk kez hazırlanmıştır. Bölgedeki diğer cevher zonları ile karşılaştırma yapabilmek için detaylı yüzey haritası hazırlanmıştır. Yapılan çalışmada cevherin Orta Kambriyen yaşlı Çaltepe formasyonu içerisinde yer aldığ 1 , epijenetik oluşumlu olduğu, tek bir karbonatlı seviyede görüldüğü ve stratabound karakterli olduğu belirlenmiştir. Cevher parajenezi sfalerit, galenit, pirit, kalkopirit, simitsonit, zinkit ve limonitten oluşmaktadır. Cevher mineralojisi ve jeokimyası değerlendirildiğinde Horzum Bölgesindeki diğer yataklara benzer bir karakter sergilediği tespit edilmiştir. Düşük $\mathrm{Cu}$ oranları dünyadaki karbonat ornatım yataklarına benzerdir. Yapılan yer altı sondajları cevher eğiminin güneydoğuya olduğunu ve cevher karakterinin de yüzeydeki cevher zonlarına benzer olduğunu göstermektedir.

\section{TEŞEKKÜR}

$\mathrm{Bu}$ çalışma Kahramanmaraş Sütçü İmam Üniversitesi, Bilimsel Araştırma Projeleri Koordinasyon Birimi tarafindan 2018/7-30YLS numaralı proje tarafindan desteklenmiştir. $\mathrm{Bu}$ çalışmada desteklerini esirgemeyen Akmetal Madencilik San. ve Tic. A.Ș.'ye teşekkürlerimizi sunarız.

\section{KAYNAKLAR}

1. Ketin, İ., 1966. Anadolu'nun Tektonik Birlikleri. MTA Dergisi, 66, 20-34.

2. Okay, A.I., Tüysüz, O., 1999. Tethyan Sutures of Northern Turkey. Geol. Soc. London Spec. Publ. 156, 475-515.

3. Reynolds, N., Large, D., 2010. Tethyan Zinclead Metallogeny in Europe, North Africa, and Asia. Soc. Econ. Geol. Spec. Publ. 15, 339-365.

4. Richards, J.P., 2015. Tectonic, Magmatic and Metallogenic Evolution of the Tethyan Orogeny: from Subduction to Collision. Ore Geol. Rev. 70, 323-345. 
5. Yiğit, Ö., 2009. Mineral Deposits of Turkey in Relation to Tethyan Metallogeny: Implications for Future Mineral Exploration. Econ. Geol. 104, 19-51.

6. Hanilçi, N., Öztürk, H., Kasapçı, C., 2019. Carbonate-hosted $\mathrm{Pb}-\mathrm{Zn}$ deposits of Turkey. Chapter 10 In: Pirajno, F., Dönmez, C., Şahin, M.B. (Eds.), Mineral Resources of Turkey, Modern Approaches in Solid Earth Sciences. Springer Nature, Switzerland, 497-533.

7. Özgül, N., 1976. Some Geological Aspects of the Taurus Orogenic Belt (Turkey). Bull Geol Soc Turk 19:65-78 (in Turkish with English Abstract).

8. Kuşçu, M., 1985. Göktepe (Ermenek-Konya) Yöresinin Pb-Zn Zuhurları. TJK Bülteni, 28, 35-46.

9. Ayhan, A., Erbayar, M., 1985. Batı Zamantı (Aladağlar-Yahyalı) Karbonatlı Pb- Zn Yataklarının Jeokimyasal Prospeksiyonu. MTA Dergisi, 105, 75-84.

10. Temur, S., 1989a. Bolkardağ (Ulukışla-Niğde) Yöresi Çinko-kurşun Yataklarının İncelenmesi. Selçuk Üniversitesi Araştırma Projesi No: 659, Konya, 120.

11. Temur, S., 1991. Bolkardağ (Ulukışla-Niğde) Yöresi Zn-Pb Yataklarının Jenetik Özellikleri. Çukurova Ünv. M.M.F. Jeoloji Müh. Böl. Ahmet Acar Jeol. Semp. Bildirileri. 191-198.

12. Temur, S., 1992. Bolkardağı Yöresi Zn-Pb Yataklarının Jeokimyasal İncelemesi, TJK Bülteni, 35(2), 101.

13. Temur, S., 1996. Horzum (Kozan-Adana) ve Bolkardağı (Ulukışla Niğde) Yöreleri Zn-Pb Yataklarına Ait Piritlerin Iz Element Konsantirasyonlarının Karşılaştırılması. KTÜ, Jeoloji Müh. Böl. 30. Y1l Sempozyum Bildirileri, Trabzon, 67-81.

14. Demir, N., Bingöl, E., 2000. Aladağlar Bölgesi Oksit Karbonat Tipi Zn-Pb Yataklarının Yapısal Jeoloji ile Ilişkileri. Cumhuriyetin 75. Yıldönümü Yerbilimleri ve Madencilik Kongresi, MTA, Ankara, 573-589,

15. Kuşçu, M., Cengiz, O., 2001. Karbonatlı Kayaçlara Bağlı Orta Toroslar Zn-Pb Cevherleşmelerinin Kükürt İzotopları Incelemesi. TJK Bülteni, 44(3), 59-73.

16. Yalçın, M.G., Metin, S., Altuncu, S., Çiftçi, E., 2001. Germanium Contents of Carbonate-
Hosted $\mathrm{Pb}-\mathrm{Zn}$ Ores Occuring in Aladağ District (Zamant1-Niğde). Geosound, 40/41, 29-38.

17. Yalçın, M.G., Altuncu, S., 2000. Meydan Yaylası (Niğde) Civarı Karbonatlı ÇinkoKurşun Yataklarının Mineralojisi ve Jeokimyasal Özellikleri. GeosoundYerbilimleri Dergisi, Adana, 37, 73-86.

18. Hanilçi, N., 2003. Orta ve Doğu Toroslarda Karbonatlar İçindeki Zn-Pb Yataklarının Oluşumu, İstanbul Üniversitesi Fen Bilimleri Enstitüsü, Yayınlanmamış Doktora Tezi, 166.

19. Hanilçi, N., Öztürk, H., 2003. Aladağlarda Karbonatlar İçindeki Pb-Zn Yataklarında Duraylı Kükürt İzotopu ve Mikrotermometrik İncelemeler, Doğu Toroslar, Türkiye. 56. Türkiye Jeoloji Kurultayı, Bildiri Özleri Kitabı, Ankara, 112-114.

20. Hanilçi, N., Öztürk, H., 2005. Mississippi Valley Type $\mathrm{Zn}-\mathrm{Pb}$ Deposits in the AladağlarZamantı (Eastern Taurus) Region: Ayraklı and Denizovası Zn-Pb deposits, Turkey. İstanbul Earth Sci Rev. 18(2), 23-43.

21. Yalçın, M.G., Çiftçi, E., Çopuroğlu İ., 2004. Bolkardağ (Orta Anadolu-Niğde-Ulukışla) Civarında Bulunan Damar Tipi $\mathrm{Pb}-\mathrm{Zn}$ Yataklarının Mineralojik Incelenmesi. JMO 57. Türkiye Jeoloji Kurultayı, Ankara, 250-251.

22. Cengiz, O., Kuşçu, M., 2005. Geological Properties of Galena-Bearing Barite and Barite Deposits in the Central Taurides. $41^{\text {st }}$ Forum on the Geology of Industrial Minerals, ITU, 2.

23. Çiftçi, E., Demirören, S.S., 2011. Orta Toroslar $\mathrm{Pb}-\mathrm{Zn}$ Damar Yataklarının Kurşun İzotop Karakteristikleri. TUBITAK Proje no: ÇAYDAG-110Y016, Ankara, 150.

24. Koptagel, O., Ulusoy, U. Fallıck, A. E., 2007. Sulfur and Lead Isotope Investigations of the Carbonate Hosted $\mathrm{Pb}-\mathrm{Zn}$ Deposits in the Yahyal Region, Kayseri, Southern Turkey Turkish J. Earth Sci., 16, 57-76.

25. Hanilçi, N., Öztürk, H., 2008. AladağlarZamantı (Kayseri) Bölgesi Zn-Pb Yataklarının Jeolojisi ve Oluşumu. Türkiye Kurşun-Çinko Yataklarının Jeolojisi Madenciliği ve Mevcut Sorunları Sempozyumu, 1-04 May1s 2008, İstanbul, Türkiye, 184-199.

26. Hanilçi, N. Öztürk, H., 2010. Geochemical/ isotopic Evolution of $\mathrm{Pb}-\mathrm{Zn}$ Deposits in the 
Central and Eastern Taurides, Turkey. International Geology Review, 1-30.

27. Gümüş, L., Kumral, M., Yalçın, C., Kaya, M., Ünlüer, T.A., Öztürk, S., Karaman, M., 2018. Aladağ Birliği (Çayarası-Alanya) İçerisinde Karbonatlı Kayaçlar ile İlişkili Baritli Zn-Pb Cevherleşmesinin Jeolojisi ve Jeokimyası. Ömer Halisdemir Üniversitesi Mühendislik Bilimleri Dergisi, Kapadokya Yerbilimleri Sempozyumu Özel Sayıs1, 7(3), 1209-1213.

28. Özbek, A.C., 2014. Orta ve Doğu Toroslarda Bulunan Karbonat Yankayaçlı Pb-Zn Cevher Oluşumlarının Alterasyon Mineralojisi ve Durayl1 Izotop Nitelikleri, İstanbul Teknik Üniversitesi, Fen Bilimleri Enstitüsü, Yüksek Lisans Tezi, İTÜ, 101.

29. Megaw, P., 2015. Horzum Çinko-Kurşun Bölgesi Cevherleşmesinin Oluşumuna Ait Rapor (Yayınlanmamış), Akmetal Madencilik, 120.

30. Akyüz, F., 2019. Horzum-Kozan (Adana) Bölgesindeki Karbonat Kayaçlarda Oluşan PbZn Cevherleşmelerinin Kökeni. Yüksek Lisans Tezi, Çukurova Üniversitesi, 128.

31. Akmetal, M., 2015. Horzum Kurşun/çinko Sahas1 [Horzum Lead/Zinc Licenced Mine Area]. http:// www.akmetalmadencilik.com/ horzum-kursuncinko-sahasi. Erişim, $10 \mathrm{Kasım}$ 2020.

32. Temur, S., 1986. Genetic Study of Pyritebearing Zinc-lead Deposits in the Horzum (Kozan-Adana) District. Bull Earth Sci, 13, 31-48.

33. Işık, V., 2016. Torosların Jeolojisi; Türkiye Jeolojisi Ders Notu. Ankara Üniversitesi, Jeoloji Mühendisliği Bölümü, Ankara.

34. Şengör, A.M.C., Yılmaz, Y., 1981. Tethyan Evolution of Turkey, a Plate Tectonic Approach. Techtonophysics; 75, 81-241.

35. Özgül, N., Gedik, I., 1973. Orta Toroslar'da Alt Paleozoik Yaşta Çaltepe Kireçtaşı ve Seydişehir Formasyonunun Stratigrafisi, Konodont Faunası Hakkında Yeni Bilgiler. TJK Bülteni, 16, 39-52.

36. Özgül, N., Kozlu, H., 2002. Kozan-Feke (Doğu Toroslar) Yöresinin Stratigrafisi ve Yapisal Konumu ile İlgili Bulgular. TPJD Bülteni, 14(1), 1-36.
37. Bedi, Y., Usta., D., 2006. Tufanbeyli-FekeKozan Dolayının Paleozoyik Stratigrafisi (Doğu Toroslar). Türkiye Stratigrafi Komitesi 6. Çalıştayı. Toros Kuşağı ve Güneydoğu Anadolu Bölgesi Prekambriyen-Paleozoyik Kaya Birimlerinin Litostratigrafi Adlamaları, Özler Kitab1, 22-23.

38. Usta, D., Usta, M., Balc1, V., Kop, A., 2013. Doğu Toroslar'in Jeolojisi ve Metalojenezi (Kozan/Feke/Adana) MTA Raporu. No. 11635, 150. Ankara.

39. Dean, W., Özgül, N., 1979. Orta Toroslarda Çaltepe Formasyonu'nun Bağbaşı (HadimKonya) Yöresindeki Yüzeylemesinde Bulunan Orta Kambriyen Trilobitleri, M.T.A. Derg., 92, 1-6, Ankara.

40. Blumenthal, M.M., 1952. Yüksek Aladağ Silsilesinin Coğrafyası, Stratigrafisi ve Tektoniği Hakkında Etüdler. MTA Yayınları Seri D, 7, 136 .

41. Usta, D., Şenel, M., Metin, Y., Bedi, Y., Vergili, Ö., Usta, M., Balcı, V., Kuru, K., Tok, T., Özkan, M.K., Kop, A., 2004. KozanTufanbeyli (Adana) Arasındaki Yapısal Birimlerin Jeolojik Özellikleri, 57. Türkiye Jeoloji Kurultayı Bildiri Özleri, 275-276.

42. Jaffey, N., 2001. The Cenozoic Evolution of the Strike-slip Ecemiş Fault Zone and its Implications for the Mechanism of Tectonic Escape in Anatolia. Thesis Submitted for the Degree of Doctor of Philosophy, Edinburgh University, 150.

43. Hanilçi, N., Öztürk, H., 2011. Geochemical/ Isotopic Evolution of $\mathrm{Pb}-\mathrm{Zn}$ Deposits in the Central and Eastern Taurides, Turkey. Int Geol Rev, 53(13), 1478-1507.

44. Zhou, J.X., Huang, Z.L., Lv, Z.C., Zhu, X.K., Gao, J.G., Mirnejad, H., 2014. Geology, Isotope Geochemistry and ore Genesis of the Shanshulin Carbonate-hosted $\mathrm{Pb}-\mathrm{Zn}$ Deposit, Southwest China. Ore Geology Reviews, 63, 209-225.

45.Zhou, J.X., Bai, J.H., Huang, Z.L., Zhu, D., Yan, Z.F., Lv, Z.C., 2015. Geology, Isotope Geochemistry and Geochronology of the Jinshachang Carbonate-hosted $\mathrm{Pb}-\mathrm{Zn}$ Deposit, Southwest China. Journal of Asian Earth Sciences, 98, 272-284. 
46. Uras, Y., Yalçın, C., Balaban, A., 2019. Geology and Geochemistry of Carbonate Hosted Pb-Zn Deposit on North-East Part of Kahramanmaraş (Helete) in Engizek Belt, Çukurova University Journal of the Faculty of Engineering and Architecture, 34(3), 1-9, ISSN 1019-1011.

47. Megaw, P.K.M., Ruiz, J., Titley, S.R., 1988. High-temperature, Carbonatehosted $\mathrm{Ag}-\mathrm{Pb}-\mathrm{Zn}$ $(\mathrm{Cu})$ Deposits of Northern Mexico. Economic Geology 83, 1856-1885.

48. Demirela, G., 2011. Çataltepe (Lapseki/ Çanakkale) $\mathrm{Pb}-\mathrm{Zn}-\mathrm{Cu}-\mathrm{Ag}$ Yatağının Jeolojisi ve Kökeni, AÜ Fen Bilimleri Enst. Doktora Tezi, 220. (yayımlanmamış). 